\title{
Editorial
}

\section{Giovanni Barla}

Published online: 4 August 2009

(C) Springer-Verlag 2009

It has become a tradition for the Rock Mechanics and Rock Engineering Journal to publish the thesis annually selected by the International Society for Rock Mechanics (ISRM) for the Rocha Medal award in the form of a paper. The present issue is dedicated to the thesis by Dr Mark Ask from Sweden, who received the Rocha Medal and presented his thesis at the 4th Asian Rock Mechanics Symposium, Singapore, in November 2006.

Mark was born and educated in Sweden. He completed his $\mathrm{PhD}$ studies at the Royal Institute of Technology, Stockholm, in 2004, during which he also spent periods at the Institute de Physique du Globe de Paris and the Luleå University of Technology. Dr Ask is currently working as a consultant in rock stress and rock stress measurements at Vattenfall Power Consultant AB, Luleå, Sweden.

The 2006 Rocha Medal was unique for two different reasons. It was the first time that the medal was awarded to a student from Scandinavia. It was also the first time that the medal was given to a "collection thesis", i.e. a thesis which comprises an extended abstract and publications made during the course of the PhD work.

This in fact posed somewhat of a problem as most of the material included in the thesis had already been published in Conference Proceedings and International Journals. As a consequence, Mark was asked to re-phrase the submitted text in order to avoid obvious citations or clear repetitions. Furthermore, most of the figures were also modified and now appear quite different from the already published material. We would like to thank Mark for his kind effort.

We found nothing to prevent us from publishing the paper which was co-authored by Dr Mark Ask, together with Professor Maria Ask, Francoise Cornet, and Ove Stephansson. In fact, it is true that in the present case, as in most cases, a thesis is developed and written in close cooperation with the thesis advisers.

G. Barla $(\square)$

Dipartimento di Ingeneria Strutturale, Politecnico di Torino, Corso Duca degli Abruzzi 24, 10129 Turin, Italy

e-mail: giovanni.barla@polito.it 
The paper presents a novel strategy for evaluating the complete stress field and its variation with depth using the integrated stress determination method (ISDM). The ISDM technique involves a number of steps that need to be considered for reliable stress estimation, and these have been highlighted. It was developed as a means of integrating different types of stress data and it has successfully been extended over the years to include the most common methods for in situ stress determination. 